
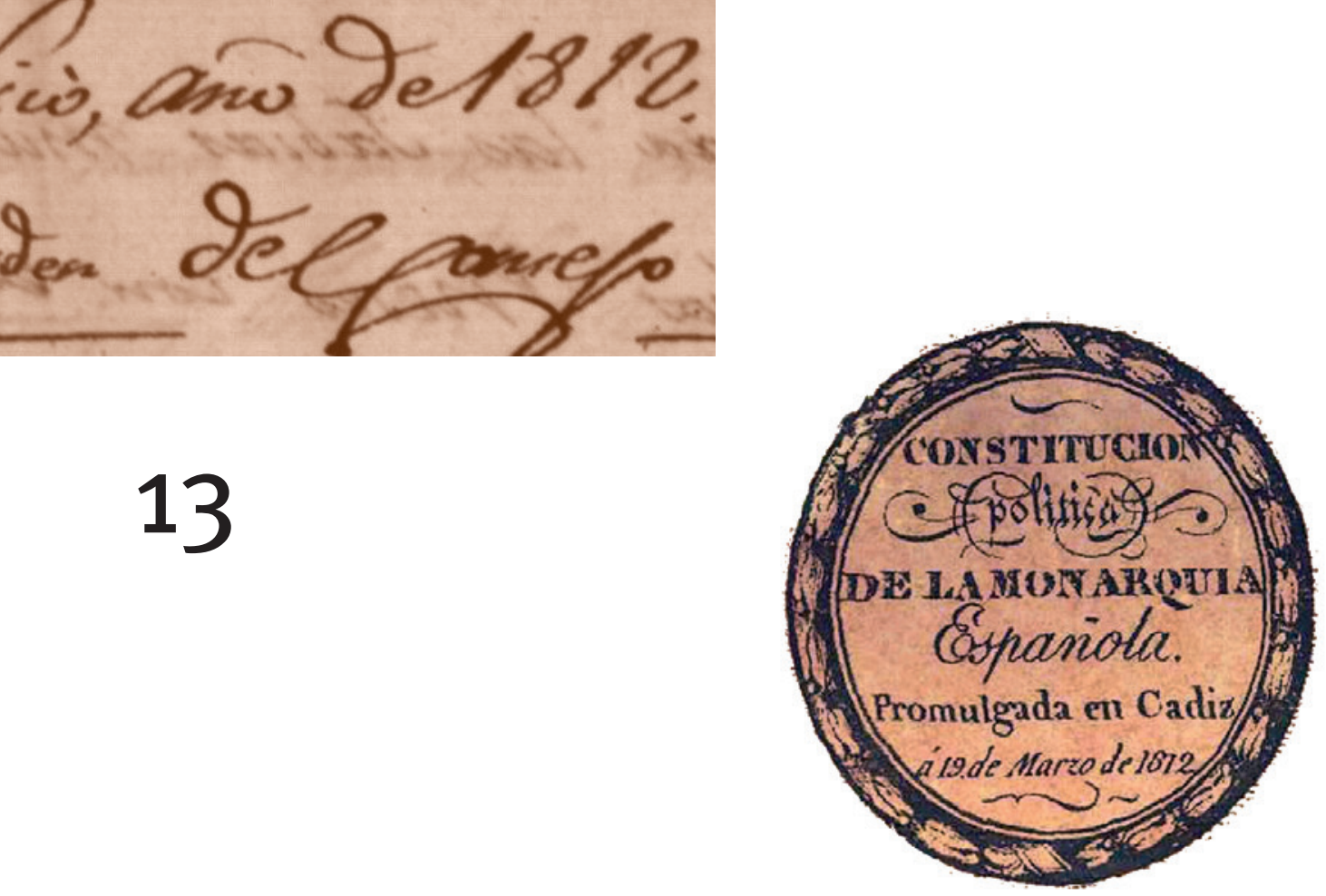

13

romulgada en Cadiz
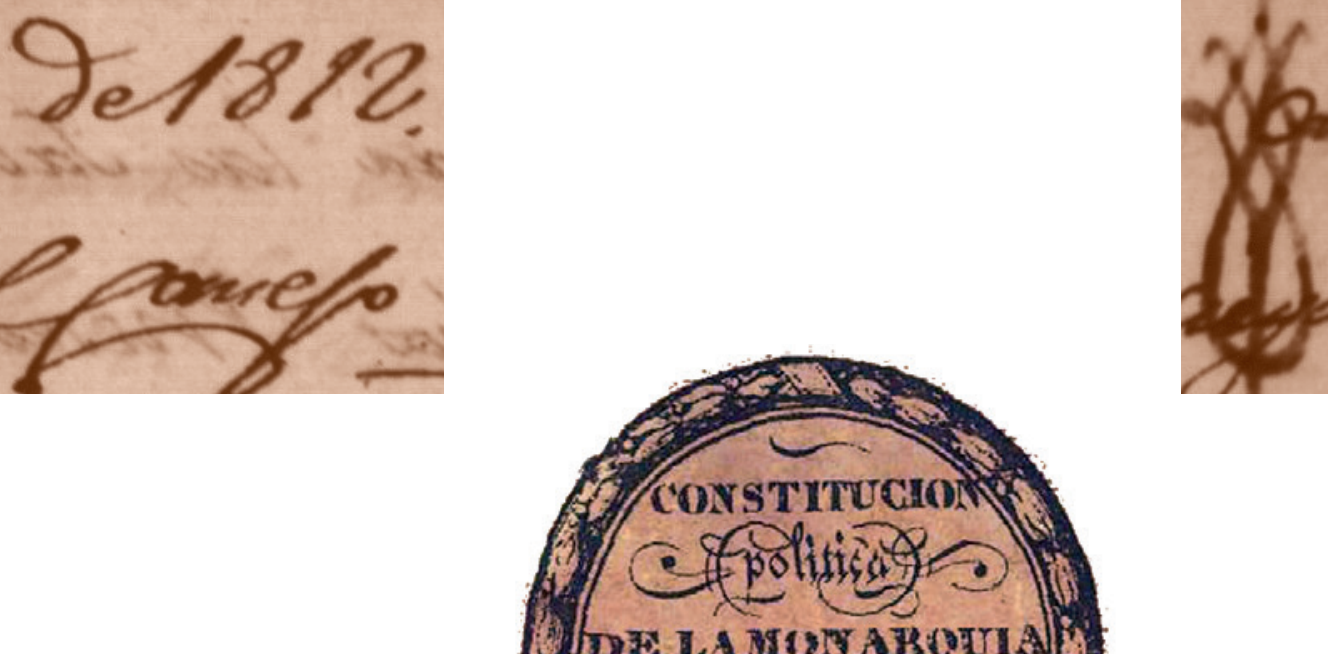



\section{Colección $\mathbf{I m u d}$ \\ n. ${ }^{\text {13 }}$}

\section{LA PROVINCIA DE LA MANCHA Y LA CONSTITUCIÓN DE 1812}





\section{Carlos Chaparro Contreras \\ e Isidro Sánchez Sánchez (eds.)}

\section{LA PROVINCIA DE LA MANCHA Y LA \\ CONSTITUCIÓN DE 1812}

Ediciones de la Universidad

de Castilla-La Mancha

Cuenca, 2021 
LA PROVINCIA de La Mancha y la Constitución de 1812 / editores, Carlos Chaparro Contreras, Isidro Sánchez Sánchez.- Cuenca : Ediciones de la Universidad de Castilla-La Mancha, 2020

341 p. ; 24 cm.- (Almud ; 13)

ISBN 978-84-9044-311-8

1. España - Constitución - 1812 2. Castilla-La Mancha - Historia I. Chaparro Contreras, Carlos, ed. lit. II. Sánchez Sánchez Isidro, ed. lit. III. Universidad de Castilla-La Mancha, ed. IV. Serie

342.4(460)"1812"

946.028

1DSE-ES-G

NHD

(C) de los textos e imágenes: sus autores.

(C) de la edición: Universidad de Castilla-La Mancha.

Edita: Ediciones de la Universidad de Castilla-La Mancha y Centro de Estudios de Castilla-La Mancha.

Colección Almud n. ${ }^{\circ} 13$.

Diseño de la colección:

C.I.D.I. (Universidad de Castilla-La Mancha).

unte Unión de Edtorlales
Universitarias Españolas nacional.

Esta editorial es miembro de la UNE, lo que garantiza la difusión y comercialización de sus publicaciones a nivel nacional e inter-

ISSN: $1988-0979$

I.S.B.N.: 978-84-9044-311-8 (Edición impresa)

I.S.B.N.: 978-84-9044-434-4 (Edición electrónica)

D.O.I.: http://doi.org/10.18239/alm_2021.13.00

D.L.: CU 248-2019

Composición: Compobell S.L.

Impresión: Gráficas Izquierdo

Hecho en España (U.E.) - Made in Spain (U.E.)

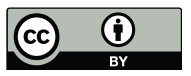

Esta obra se encuentra bajo una licencia internacional Creative Commons CC BY 4.0.

Cualquier forma de reproducción, distribución, comunicación pública o transformación de esta obra no incluida en la licencia Cretative Commons CC BY 4.0 solo puede ser realizada con la autorización expresa de los titulares, salvo excepción prevista por la ley. Puede Ud. acceder al texto completo de la licencia en este enlace: https://creativecommons.org/licenses/by/4.0/deed.es 


\section{ÍNDICE}

Presentación ..................................................................................

Gabino Marco Solera, Carmen María Montalbán Martínez y Antonio Ruiz Lucas

Las Cortes y la Constitución de Cádiz: contenidos sociales y esperanzas populares

Juan Sisinio Pérez Garzón

La Constitución de 1812

Enrique Belda Pérez-Pedrero

Guerra y revolución en La Mancha Ángel Ramón del Valle Calzado

El Partido de Alcaraz a finales del Antiguo Régimen

65 Carmen Hernández López y Francisco García González

"Napoleón emperador" y el destino del Partido de Almagro......... José Gregorio Cayuela Fernández

La Mancha, 1812: El partido judicial de Villanueva de los Infantes Lucía Crespo Jiménez

Representación y educación político-popular en las ceremonias y fiestas de proclamación y jura de la Constitución de 1812 en La Mancha

Carlos Chaparro Contreras

La crisis del Antiguo Régimen en La Mancha (1787-1808). El caso de Villanueva de los Infantes y su partido.... Carlos Javier Rubio Martínez 
Los manchegos que auparon a la "Pepa"

Enrique Jiménez Villalta

Almadén y la Constitución de Cádiz (1812-1814)

245

Julián Prior Cabanillas

El padre Agustín de Castro y la prensa periódica

273 Isidro Sánchez Sánchez 


\title{
LA MANCHA, 1812: EL PARTIDO JUDICIAL DE VILLANUEVA DE LOS INFANTES
}

\author{
LUCÍA CRESPO JIMÉNEZ \\ UNIVERSIDAD DE CASTILLA-LA MaNCHA
}

La realidad administrativa que hoy engloba el partido judicial de Villanueva de los Infantes no se ajusta estrictamente al territorio que aquél comprendía a principios del siglo XIX. Por entonces, el partido se enmarcaba en los límites de la provincia de La Mancha, que se había creado en 1691 a partir de la segregación de una parte de los vastos territorios que hasta entonces constituían la provincia de Toledo (concretamente los que corresponden a los partidos de Alcaraz, Almagro, Ciudad Real e Infantes). De acuerdo con esta primera división, el partido judicial de Villanueva de los Infantes se correspondería, a grandes rasgos, con la realidad histórico-geográfica del Campo de Montiel.

Las posteriores iniciativas de reorganización provincial, como la de Floridablanca (Nomenclátor de 1785), no afectaron sustancialmente a La Mancha ni a sus territorios hasta la división administrativa de Javier de Burgos en 1833. Sí se operaron algunos cambios internos, como el que afectó al partido de Infantes, bajo cuya tutela administrativa quedaron a partir de 1799 los pueblos de la Orden de Santiago que formaban la Mesa de Quintanar (el propio Quintanar, Campo de Criptana, el Toboso, Tomelloso, Socuéllamos, Villamayor de Santiago, Cabezamesada, Hinojoso de la Orden y Santa María de los Llanos, entre otros) y algunas poblaciones del Priorato de San Juan. Se configura así una realidad administrativa muy extensa, que abarca territorios de las actuales provincias de Toledo, Cuenca, Ciudad Real e, incluso, Jaén (como Beas de Segura).

En cuanto al marco cronológico en que se encuadra este trabajo, existe sin duda una realidad histórica muy concreta que lo define: la de la guerra de la independencia, que transcurre entre los años 1808 
y 1814. No es mi intención detenerme en el relato de los hechos bélicos que se desarrollan en este periodo en el partido, pues existen ya muchas aportaciones en ese terreno, sino que he optado por centrarme en otras realidades de índole política, económica y social que me permitirán ilustrar un proceso más amplio y de más hondo calado. Me estoy refiriendo a la crisis del Antiguo Régimen y el inicio de la revolución liberal.

La citada crisis se habría manifestado en una triple dirección. Tendría, en primer lugar, una faceta político-institucional que se habría puesto de manifiesto en la desaparición de instituciones propias del Antiguo Régimen, como el mayorazgo, el señorío o la Inquisición, pero sobre todo en el descrédito de los estamentos privilegiados (nobleza y clero) por su incapacidad para hacer frente a la invasión. La crisis adquiriría también una dimensión económica, manifiesta en la liquidación de las relaciones señoriales de producción y la progresiva mercantilización de las mismas. Y, por supuesto, una implicación socio-cultural, que se traduciría en el desmoronamiento de los esquemas tradicionales y lo que algunos historiadores han identificado con una "relajación de las costumbres", lo cual habría afectado al modo en que la sociedad percibía ciertos fenómenos, como el hecho religioso o las propias instituciones del Antiguo Régimen.

Vamos a ver cómo se concretan estas afirmaciones generales en el partido de Infantes, cuáles son los elementos propios que definen su realidad histórica frente a estos procesos. Empezaremos examinando los aspectos políticos, cómo se desintegran o transforman los poderes tradicionales.

\section{LA DESINTEGRACIÓN DE LOS PODERES TRADICIONALES}

Durante la guerra de independencia, los pueblos del partido de Villanueva de los Infantes fueron escenario de un continuo intercambio de fuerzas entre las tropas napoleónicas de camino hacia Andalucía, el ejército patriótico y la resistencia popular (no en vano por estas tierras transcurría la principal vía de comunicación hacia el sur de la península). En semejante contexto, se alternaron en la zona dos autoridades contrapuestas, así como dos realidades administrativas diferentes que, además, representaban dos proyectos políticos igualmente enfrentados: el bonapartista (o afrancesado) y el liberal.

\subsection{Las Juntas de Defensa y Gobierno, institución vehicular del proyecto liberal}

En los primeros meses de la invasión, en ausencia de un poder legítimo que vertebrara la vida política y social de las poblaciones del par- 
tido, fueron las Juntas de Defensa y Gobierno las que se erigieron en representantes de la soberanía nacional y de la propia autoridad monárquica ausente. Su importancia fue capital en la organización de la resistencia, tanto como en la canalización del proyecto liberal en ciernes, una vez las instituciones del Antiguo Régimen demostraron su incapacidad para hacer frente a la invasión y, tanto más importante, para garantizar la seguridad de las poblaciones de este partido y evitar que la agitación social inherente al conflicto tomase un rumbo revolucionario.

Para articular la actividad de cada una de estas organizaciones, se creó una Junta Central establecida primero en Aranjuez y trasladada más adelante a Sevilla, a la que, no obstante, le costó imponer su autoridad, una vez las juntas locales habían probado su capacidad para gobernar su territorio de forma autónoma. Además, esta Junta Central contaba con escasos recursos para desempeñar su labor y debía hacer frente al cuestionamiento de algunos sectores que abogaban por el establecimiento de una regencia como delegada legítima del poder real en el exilio. A pesar de estas limitaciones y obstáculos, esta junta se convirtió en la depositaria y máxima defensora del proyecto liberal, que trataba de llevar a todos los rincones de la geografía española a través de sus "delegadas" provinciales y municipales y, desde 1812, con la formación de los ayuntamientos constitucionales. Fue esta junta suprema la encargada de convocar las Cortes que habrían de desarrollar la reforma liberal y plasmarla en una Constitución antes de su disolución en enero de 1810, momento en que el poder pasó a manos de una regencia integrada por el obispo de Orense, Pedro Quevedo, los generales Castaños, Escaño y Fernández de León y por Francisco de Saavedra, antiguo Secretario de Estado de Carlos IV y presidente de la Junta Suprema de Sevilla.

Dicho proyecto, que aspiraba a la profunda transformación de las estructuras señoriales del Antiguo Régimen y su sustitución por un moderno Estado de corte liberal (que implicaba la sustitución del absolutismo por una monarquía constitucional, la división de poderes, la ampliación de las libertades individuales y la desaparición de instituciones como los señoríos o la Inquisición), se concretó con la promulgación de la Constitución de 1812, momento hasta el cual se desarrollaron intensos debates entre los partidarios de la reforma y quienes defendían la restauración del viejo orden. Pues como ya apuntó Pierre Vilar, a la unidad reinante frente a la agresión invasora subyacía una "contradicción fundamental: una minoría activa y políticamente muy consciente lucha a un tiempo contra Napoleón y contra el Antiguo Régimen; una masa apasionada lucha en cambio contra Napoleón como representante de un eventual régimen nuevo. 
El odio patriótico contra los franceses, sobreexcitado por sus exacciones, alimenta, pues, dos esperanzas políticas de signo contrario" ${ }^{\text {. }}$

En el partido de Infantes se crearon diversas juntas locales desde 1808, nacidas unas por la iniciativa de sus autoridades, espoleada su creación en otros casos por el requerimiento de la Junta Superior de La Mancha, que en oficio de agosto de ese mismo año urgía a su constitución en los pueblos del partido con una población de más de mil vecinos. Entre las que podemos recordar están las de Membrilla, Torrenueva o la de la propia villa de Infantes, a la que, como cabeza de partido, quedaban jerárquicamente subordinadas las anteriores.

La formación de las juntas se haría, conforme indicaba el oficio anterior y siguiendo los dictados de la Junta Suprema de Sevilla, de la siguiente forma:
"Se congrega[ría] en el Ayuntamiento a clero, prelados regulares, nobles y demás personas que por las cualidades de su probidad y luces se estimen por convenientes y por elección de estos se formará una Junta de seis personas, que reciba las órdenes de esta Superior, dé los avisos oportunos y use en todo de la autoridad que le corresponde y a quien estarán obligados a obedecer los vecinos y juez letrado en su destino y todo a él correspondiente"2.

Las personas designadas para semejante responsabilidad se distinguirían, además, "con una cinta encarnada teñida con un lazo al brazo izquierdo para que sean reconocidos y respetados por los pueblos. Además, su presidente será tratado con el honor de Excelencia y los vocales de Señorías" 3 .

Con frecuencia se ha atribuido a este tipo de organismos un carácter popular, presentándoselas como un primigenio cauce de participación ciudadana en la vida política de la nación. Sin embargo, basta con echar un vistazo a la composición de algunas de estas juntas para que el mito salte por los aires, pues a pesar de que, efectivamente, las juntas se declararon depositarias de la soberanía nacional, la participación popular en ellas fue prácticamente inexistente. Por el contrario, en la mayoría de los casos fueron las mismas elites del Antiguo Régimen (antiguos cargos públicos y también bastantes eclesiásticos) las que lideraron el movimiento juntista. Así por ejemplo, la junta infanteña, creada en 1808

1 Tomado de J. Fontana, "La época del liberalismo", en J. Fontana y R. Villares (dirs.), Historia de España, vol. 6, Barcelona, Crítica-Marcial Pons, 2007, pp. 45-46.

2 AHN, Consejos, leg. 5518, exp. 8.

3 Ídem. 
por "personas influyentes" 4 , estuvo presidida por Juan Álvarez Lorenzana hasta su muerte en 1809 , el cual había sido visitador eclesiástico y gobernador del partido de Infantes desde 1787. Le acompañaban el abogado de los Reales Consejos Antonio José Cabañero, que le sucedió en la presidencia; el vicario Ignacio Ortega, juez eclesiástico ordinario del Campo de Montiel; el regidor José Fontes Abat, Joaquín Rubio y el escribano Baltasar de Antequera García. He mencionado la de Infantes por su importancia, pero podrían ponerse otros casos como el de la junta local de Membrilla, cuya presidencia recayó en un caballero Maestrante de la Real de Ronda, Vicente María Heredia.

En cualquier caso, nos fijemos en uno u otro ejemplo, vemos que, generalmente, fueron las personalidades más importantes de la población las que se hicieron con el control de estos organismos con la pretensión de mantener a raya desde su autoridad toda posible amenaza popular. Como han señalado Araceli Monescillo y Ángel Ramón del Valle, su continuidad en el poder evidencia que lo que se rechazaron fueron las instituciones del Antiguo Régimen y no a las personas que las formaban, cuya colaboración fue bien acogida en las juntas por la necesidad de apoyos en la trágica situación que vivía el país 5 .

Entre las funciones que desempeñaron las juntas estaban la requisa y organización de los suministros para las tropas y la guerrilla o la recaudación de contribuciones; tenían también bajo su cargo la formación de partidas y batallones de voluntarios, como el que se creó en Villanueva de los Infantes; también se encargaban de las labores de propaganda e impartían justicia en los territorios de su dominio. De hecho, parece ser que fueron precisamente los desórdenes que se produjeron al principio de la guerra en estos territorios los que animaron, definitivamente, la creación de este tipo de instituciones con el objeto de representar a la autoridad competente - "debilitada con las pasadas convulsiones"- y restablecer el orden, para que aquélla "asegure el cumplimiento y feliz éxito de las providencias que se dictaren, para el mejor logro de la empresa que ocupa a toda la Nación"6.

Estas fueron, de hecho, las tareas que durante el conflicto desempeñaron las juntas, aunque inicialmente sus atribuciones no estaban nada claras para sus propios integrantes y existieron conflictos con otras dignidades sobre los límites de su autoridad. Así se sigue del oficio enviado

4 AHN, Estado, leg. 63C.

5 A. Monescillo Díaz y A. R. del Valle Calzado, "Guerra y revolución liberal (1808-1833)”, en I. Sánchez Sánchez (coord.), La provincia de Ciudad Real (II). Historia, Ciudad Real, Diputación Provincial, 1996, p. 360. En este mismo trabajo, se recoge la noticia del único ejemplo que existe en La Mancha de una junta verdaderamente popular, la de Valdepeñas, que contó entre sus dirigentes con un contrabandista, Manuel Madero, y un presbítero de ideas radicales, Juan Antonio León.

6 AHN, Consejos, leg. 5518, exp. 8. 
por la junta infanteña al Consejo de Castilla en octubre de 1808, en el que solicita que se definan exactamente sus competencias, "si éstas son sólo para lo económico y lo gubernativo" hasta que Fernando VII sea restituido en el trono, o "si se amplían a lo contencioso y a poder tomar conocimiento en todos los negocios que le controviertan; si las órdenes que antes se cumplimentaban por los Ayuntamientos deben hacerse por los que representan; si la Jurisdicción de los Jueces está expedita o con alguna sujeción o dependencia de esta Junta, sucediendo lo mismo con las subdelegaciones y demás ramos que hay en esta Ciudad y Partido"7. La respuesta del Consejo hace notar el desconcierto institucional propio de los primeros meses de la guerra, al manifestar lo siguiente:

"La autoridad que hasta ahora han ejercido de hecho y contra derecho las Juntas Supremas del Reino y subalternas, dan ocasión a las dudas que hoy ocurren. Tienen entendido los Fiscales extrajudicialmente haber dado la Suprema Junta Central ciertas providencias a este intento y se hace muy necesario tenerlas a la vista para proceder a la justa aplicación que exige la actual representación de la Junta de Infantes. Podía mandar el Consejo que estas Juntas que se han creado a sí mismas atribuyéndose toda la autoridad que les ha dictado su ambición desmedida, despojando atentadamente a las potestades constituidas por la ley, a que no han podido contravenir sin delito, no impidiesen el uso de sus funciones a los Tribunales, Jueces, Justicias y Magistrados, pero sería más conveniente representar a la Suprema Central, a fin de que tenga a bien comunicar al Consejo la orden que se haya expedido y las que expidiese sobre tan importante asunto, como necesaria para arreglar todos los casos que ocurran y aún circularse a los pueblos para que conforme a su tenor procedan en el uso de los recursos e instancias que en común y en particular se les ofreciese, así en cuanto al armamento, como en los demás negocios de justicia e intereses, restituyéndose el orden establecido por las leyes y excusando injustos atropellamientos y vejaciones y competencias que se suscitan con menoscabo de los vasallos y entorpecimiento de los negocios en deservicio del público"8.

Finalmente, el Consejo resolvió, conforme a una Real Orden dada en octubre de 1808 por la Junta Central Gubernativa que "desde el día en que recibieron por sus diputados la noticia de la instalación de la Junta Suprema cesen las de las Provincias en conceder grados y hacer promociones militares y remitan una relación de los que hubiesen acordado

7 Ídem.

8 Ídem. 
desde dicha época. Lo mismo deberá practicarse respecto a la provisión de toda clase de empleos civiles y eclesiásticos, libre ejercicio de su autoridad en los tribunales y magistraturas establecidos por nuestras leyes, imposición de tributos y cargas, y cuantas medidas [hubieren] de causar regla general. Así, se restablecerán el equilibrio y curso ordinario de los negocios y administración pública, cuyo sistema y orden no podrían de otra suerte conservarse" 9 .

A su vez, las juntas del partido de Infantes debían sujetarse a las directrices de la Junta Superior de La Mancha, constituida en Ciudad Real en mayo de 1808 bajo la presidencia de Juan Módenes. No obstante, aquéllas actuaron con gran autonomía y, en muchos casos, no se mostraron dispuestas a renunciar fácilmente a ella, lo que atomizaba el poder y dificultaba la toma de decisiones.

Paradigmático ejemplo del descontento de algunas juntas locales y su sensación de abandono por las autoridades nacionales y provinciales, es el de la junta de Villanueva de los Infantes, descontento que se debía a la falta de ayuda recibida por la Junta Suprema del Reino, así como por otras juntas provinciales a las que se dirigieron en busca de ayuda (como la de Ciudad Real, su jerárquicamente superior; o la de Granada $\left.{ }^{10}\right)$. Como ha señalado Ronald Fraser, esa sensación de abandono motivó el rechazo de algunas juntas hacia los poderes superiores y su capacidad para afrontar en solitario la amenaza francesa generó en dichos organismos una sensación de autosuficiencia, que consolidó su autoridad ${ }^{11}$. En este contexto se explica la pugna que mantuvo la junta, que se erigía en representante de los pueblos del partido judicial de Villanueva de los Infantes, con la Superior de La Mancha, establecida en Ciudad Real. Según se sigue de los documentos existentes los hechos habrían ocurrido como se detalla a continuación.

"Ocupada esta capital por el ejército francés y sin libertad las autoridades constituidas para obrar en beneficio de la Nación, se pasó circular a los vecinos de Infantes en 6 de Junio [de 1808] exhortándolos a la defensa de la Patria y a que nombrasen sujeto que pasase a la capital como su representante". En respuesta a esta orden, se habría procedido a designar inmediatamente un "apoderado" por medio del cual "se comunicasen las providencias que adoptase la Junta en beneficio de la Provincia”. El dicho representante, que fue el teniente coronel Ramón

9 Ídem.

10 Ésta habría conminado a la junta local de Villanueva de los Infantes a ponerse bajo la autoridad de la Junta Superior de La Mancha en agosto de 1808, en virtud de lo acordado por la Suprema Central de Sevilla. AHN, Consejos, leg. 5518, exp. 8.

11 R. Fraser, La maldita guerra de España, Barcelona, Crítica, 2006, pp. 385-386. Esta idea de la atomización del poder fue también expuesta por J. R. Aymes, La Guerra de la Independencia en España (1808-1814), México, Siglo Xxi, 1980. 
Antolínez de Castro, se personó en Ciudad Real el día 17 de junio, donde habría de tener lugar una junta general convocada por la Superior de La Mancha. Sin embargo, "ocurrido en Ciudad Real un alboroto popular de que resultó la muerte violenta de un oficial o persona sospechosa que con unos pliegues se había retenido en Manzanares y otras cosas", se disolvió la junta al tener que ausentarse el intendente, que era, a la sazón, presidente de la junta ciudadrealeña. Como resultado de esta circunstancia, y convencido de que no iba a recibir por parte de aquélla ningún auxilio de las vejaciones de las tropas francesas, el delegado infanteño regresó a su partido al día siguiente.

Ante la sensación de indefensión que este capítulo habría provocado, la junta de Infantes habría decidido buscar ayuda para su defensa en Granada. Tal y como la propia junta explica, "los motivos que tuvo la Junta de Infantes para entrar en correspondencia con la de Granada, consistieron en hallarse situado su Partido dentro de la jurisdicción de la Chancillería y en la necesidad urgente de recibir socorros para no experimentar el trato bárbaro con que destruían los franceses los pueblos desgraciados de Manzanares, Valdepeñas y otros de sus inmediaciones”. Sin embargo, la junta granadina les habría expresado su imposibilidad de ayudarles, por no tener recursos armamentísticos, aunque comprometiéndose a hacer llegar sus necesidades a la Suprema de Sevilla para que ésta adecuase sus planes militares. Desde entonces, dice la junta infanteña, habría quedado interrumpida la comunicación y el partido de Infantes "abandonado a las amenazas y vejaciones de los franceses".

Es en este punto cuando se hace más evidente a las autoridades locales que la defensa de su pueblo y de las poblaciones de su partido judicial deberá depender de sus propios esfuerzos. Esta necesidad de obrar por cuenta propia será el argumento que reiterará la junta infanteña una y otra vez en su defensa contra el sometimiento a la Superior de La Mancha: "no han encontrado otra protección de las Juntas, en recompensa de su celo y sacrificios que haberse visto reducidas a sus propias fuerzas para mantener su tranquilidad interior, viviendo en la continua zozobra que debía inspirarle la inmediación del enemigo y sus amenazas para obligarlo a faltar a su conocida fidelidad". E insisten en nuevo oficio de septiembre de 1808, en que "esta Junta y Partido ha concurrido a los pueblos del tránsito de las tropas francesas y nacionales con cuanto se le ha pedido y ha sido susceptible, a las primeras, por evitar las funestas consecuencias que de lo contrario pudieran haber ocurrido como ha sucedido en otros pueblos; y a las segundas por pura voluntad y obligación".

Por esta razón, cuando la junta de Ciudad Real recupera su posición tras la huida de los franceses y pretende restituir su autoridad sobre las otras juntas locales, la de Infantes se niega a renunciar a aquellas activi- 
dades que había estado gestionando hasta entonces, fundamentalmente la recaudación y el reclutamiento. Así, en respuesta a un oficio de aquélla de agosto de 1808 en que se reclamaba a la de Infantes el envío de todos los capitales en poder de los administradores o arrendatarios de las encomiendas de los señores de Infantes, ésta se niega rotundamente, haciendo notar con gran ironía cómo la junta de Ciudad Real, "silenciosa hasta esta época, parece recobró nueva vida con la derrota de Dupont y la salida de los franceses de la Corte" ${ }^{12}$.

La negativa de Infantes no sólo se justifica en la ineficacia demostrada por la junta provincial para con los pueblos dependientes de su protección, sino que se enmarca en el ya citado conflicto de competencias y el caos institucional causado por la guerra. La Junta Central se pronunció finalmente a favor de la Junta Superior de La Mancha y trató de solventar el conflicto desterrando a Antonio José Cabañero, que presidía la junta de Infantes, considerado responsable de la situación, e incluso llegó a apelar a la intimidación, amenazando con el uso de la fuerza armada si fuera necesario.

En cualquier caso, lo cierto es que, dada la situación bélica, las juntas apenas pudieron desarrollar el programa liberal más allá de actos simbólicos, el más importante de los cuales sería, sin duda, la jura de la Constitución de Cádiz, que se realizó con gran solemnidad el día 25 de julio de 1812 en Villanueva de los Infantes, donde se había instalado la itinerante Junta Superior de La Mancha (anteriormente ésta se había establecido en Santa Cruz de Mudela, La Carolina, Alcaraz y Elche de la Sierra), convirtiéndose en la primera villa de la provincia en hacerlo. No es una casualidad esta circunstancia si atendemos al hecho de que de Infantes eran naturales dos de los responsables de nuestro primer texto constitucional, los diputados Fernando Melgarejo de los Cameros y Ramón García-Giraldo, quien, además, presidió las primeras Cortes de Cádiz.

Aunque en este mismo congreso tendremos la oportunidad de escuchar un trabajo específicamente dedicado a este aspecto, me gustaría exponer brevemente el modo en que se producía este acto tan simbólico: el ejemplar de la Constitución, así como los decretos de la Junta Central que exigían su juramento y reglaban el modo de hacerlo y un gran cuadro con la efigie de Fernando VII llegaban a las localidades de manos de unos comisionados, que eran los encargados de ejercer de maestros de ceremonias. En el partido de Infantes ostentaron tal dignidad Luis de Ulloa, caballero de la Orden de Santiago y Antonio José Cabañero, abogado de los Reales Consejos y presidente de la junta local; en Albaladejo lo hizo Alfonso Teatino Valero, regente de la Real Jurisdicción; y en Osa de Montiel, Rafael Manuel de Lomas Alfosea, alcalde mayor.

12 Todas las referencias al conflicto entre las juntas de Ciudad Real e Infantes, se han extraído de AHN, Consejos, leg. 5518, exp. 8. 
El primer acto requerido era la lectura pública y solemne de la Constitución, que solía hacerse en el lugar más principal de la villa, generalmente la plaza pública. Para acentuar el júbilo y la importancia del acto, en algunas localidades del partido se dieron corridas de toros y vaquillas. La jura propiamente dicha solía llevarse a cabo al día siguiente en la iglesia parroquial (en Infantes también se hizo en los conventos de clausura de la Encarnación y Santa Clara), durante el transcurso de una misa, en la cual la Constitución era colocada junto a los Evangelios; el primero en hacer el juramento era el alcalde que, a continuación, se lo tomaba al regidor y demás autoridades, clérigos y personalidades notables de la población. Finalmente, tras la jura, para darle aún mayor solemnidad al evento, se cantaba un Te Deum.

La jura de la Constitución fue sucediéndose por los pueblos del partido de Infantes progresivamente, conforme los franceses iban retirándose de sus tierras, sujetándose las distintas poblaciones al mismo ritual que había tenido lugar en Villanueva de los Infantes en julio de 1812: un mes más tarde tuvo lugar en Cañamares, Montiel, Osa de Montiel y Villahermosa; en septiembre jurarían la Constitución Alhambra, Carrizosa, Fuenllana, La Solana y Torrenueva; y a lo largo de octubre lo harían Albadalejo, Membrilla y Villamanrique; en noviembre se sabe que los actos tuvieron lugar en Castellar de Santiago; en el extremo del partido, en El Hinojoso de la Orden, la jura no tuvo lugar hasta el mes de diciembre. Puede así dibujarse un mapa de la incipiente evolución del liberalismo en el partido de Infantes que, no obstante, quedó reducido a un mero hecho simbólico pues, una vez acabada la guerra de independencia, tras la vuelta de Fernando VII, el rey derogó la obra legislativa de las Cortes de Cádiz y se restableció el absolutismo, así como el entramado institucional propio del Antiguo Régimen.

\subsection{La autoridad bonapartista sobre el partido de Infantes}

Con avances y retrocesos simultáneos, puede decirse que el territorio correspondiente al partido judicial de Villanueva de los Infantes permaneció bajo la órbita de los ejércitos y autoridades invasoras la mayor parte del tiempo comprendido entre 1810 y 1812 como, en general, lo haría la provincia de La Mancha. Aunque, ciertamente, no hubo asentamiento de la autoridad afrancesada en los territorios del partido, aquélla sí se estableció muy cerca, en el pueblo de Manzanares, lo que convirtió a esta zona en un área estratégica para vigilar el movimiento de las tropas invasoras por la provincia ${ }^{13}$.

13 Así, por ejemplo, Emeterio Celedonio de Barredo informaba al general Blake, en comunicación de agosto de 1810, cómo "los enemigos se han retirado de Villahermosa y de Infantes, pero 
La propia villa de Infantes fue objeto el 6 de marzo de 1811 de un enfrentamiento entre las tropas francesas y los ejércitos patrióticos comandados por el teniente coronel de infantería Luis Ulloa. El propio Ulloa relata en un informe posterior cómo el día 4 de marzo tuvieron noticia de la salida de una columna volante enemiga de Infantes hacia el Bonillo y otros pueblos de la Mancha y cómo entonces desarrolló el siguiente plan: hacer un movimiento con las cuatro compañías de Infantería de Cazadores de La Mancha sobre la retaguardia del enemigo. Con ese objeto salió desde Alcázar el día 5 de marzo, llegando a Villanueva de la Fuente. Decidió entonces atacar a los franceses en Infantes, lo que consiguió con éxito. A resultas de este enfrentamiento los franceses perdieron treinta soldados, un capitán y dos subalternos, quedando heridos más de cincuenta, entre ellos el comandante interino. Entre los españoles se contaron tres bajas de soldados y veintidós heridos, entre ellos los subtenientes Manuel Marín y Alfonso Herrera. Destaca Ulloa especialmente la acción del capitán José Espuche y Lorenzo, a quien correspondió el honor de romper el cerco francés ${ }^{14}$.

La continua inestabilidad en que sumían a las tierras del partido acciones como la que se acaba de relatar impidió a las autoridades bonapartistas desarrollar su proyecto reformista. Los nuevos poderes intentaron poner en marcha una reforma moderada de las estructuras políticas y sociales del Antiguo Régimen, inspirada en las ideas ilustradas y tendente a evitar todo avance revolucionario ${ }^{15}$. Pero, como ha apuntado Josep Fontana, la coyuntura bélica no fue la única dificultad que los reformadores encontraron para desarrollar su plan, sino que habría que tener también en cuenta la falta de recursos e, incluso, la escasa autoridad de las fuerzas napoleónicas, que allí donde habían logrado imponerse sólo habían conseguido el sometimiento militar de la población ${ }^{16}$.

Tan sólo una porción de la población se mostró favorable a la idea reformista de José I y colaboró en su desarrollo: son los llamados afrancesados. Entre sus filas había clérigos y personas ilustradas, funcionarios y personal subalterno de la administración. No formaban, sin embargo, un grupo compacto y homogéneo, sino que habría que distinguir entre quienes colaboraron con las nuevas autoridades por la profunda convicción de la necesidad de esta transformación -hablaríamos entonces de un afrancesamiento de tipo político o ideológico, grupo en el que

ha salido de Manzanares la división ambulante del Coronel de Dragones, que ayer se hallaba en Argamasilla de Alba y en Tomelloso". AHN, Diversos-Colecciones, leg. 128, exp. 23.

14 AHN, Diversos-Colecciones, leg. 202, exp. 10.

15 Para un conocimiento en profundidad de este proyecto y sus ideólogos, puede consultarse el trabajo, ya clásico, de M. Artola, Los afrancesados, Madrid, Alianza Editorial, 2008 (reedición del original, de 1976).

16 J. Fontana, ob. cit., p. 51. 
podríamos englobar, por ejemplo, a Isidro María Buenache, alguacil mayor de millones de Infantes, que poseía incluso una vivienda popularmente conocida como "Casa Godoy" o a Diego Tomás Ballesteros, quien fue regidor de la misma villa ${ }^{17}-\mathrm{y}$ aquellos que lo hicieron apremiados por la necesidad de mantener el jornal con el que se mantenía su familia -es éste un tipo de colaboracionismo económico- o porque, sencillamente, fueron obligados a hacerlo bajo amenaza de perder la propia vida. En cualquier caso, acabada la guerra, no importó la motivación que impulsó su participación en el proyecto afrancesado y todos ellos fueron represaliados por las autoridades fernandinas.

No obstante, el hecho de que la mayoría de las instituciones del régimen bonapartista se establecieran fuera del partido de Infantes (la mayoría se concentraron en Almagro, como la Administración de Rentas Reales o las Contadurías de la Mesa Maestral y de Reales Maestrazgos) limita el impacto del afrancesamiento en el partido. En la mayoría de los casos los testimonios encontrados dan fe de cómo en cada pueblo ocupado por los franceses, el miedo provocado por la amenaza física o la exigencia por parte de los franceses de un juramento de fidelidad al nuevo rey, José I, motivó la huída de las autoridades locales de las poblaciones para no verse comprometidas. Tal fue el caso de la junta de Infantes, que, en oficio de agosto de 1809, narra cómo "ocupada la mayor parte de sus pueblos por los franceses, y cometiendo estos las mayores impiedades y robos, se vio precisada a dispersarse huyendo sus individuos a la sierra, libertando así la vida aunque con abandono de sus casas y caudales, pero conservando la fidelidad que prometieron a su Amado y Legítimo Soberano el Sr. D. Fernando el $7^{\circ}$ [sic] (que Dios guarde)" 18 .

De esta huida se sigue uno de los episodios más rocambolescos habidos en esta población durante la ocupación francesa, que tiene mucho que ver con todo este juego de lealtades al que me vengo refiriendo. Al haber fallecido poco antes de estos hechos el Gobernador y, a la sazón, presidente de la Junta, se decidió nombrar por interino al alcalde mayor, "sin más mérito que el de el [sic] honor de la Jurisdicción y para conservar más así su autoridad”. Pero tan pronto como se dispersó la junta, bien por temor al enemigo o "por efecto de su limitado talento", comenzó aquél a suministrar abundantes víveres a los franceses, afincados en La Solana y Valdepeñas, "exigiendo los Renglones que pedían de las fortunas particulares, ya en carne, pan, vino, caballerías de tiro y

17 Citado por C. J. Rubio Martínez, La crisis del Antiguo Régimen en el Campo de Montiel (1787-1808). Memoria de actividades del 203 aniversario del seis de junio, Ciudad Real, Asociación Histórico-Cultural Seis de Junio de 1808, 2010, p. 48.

18 AHN, Estado, leg. 83T. 
otros efectos, acordando únicamente sus resoluciones con unos cuantos del pueblo y el Regidor D. Miguel Ortega, que sólo quedaron en él por conservar sus peculios o por otros fines poco decorosos". Pero, tanto más grave que el abastecimiento a los ejércitos invasores resultó que el alcalde mayor regidor jurase fidelidad al "rey intruso", José I, "en acto solemne, ante el Señor Sacramentado en la Iglesia parroquial".

Asimismo, informan de que el citado alcalde, en compañía de un eclesiástico "que suponía hacer las veces del párroco” y otros, dispusieron

\begin{abstract}
“pasar a la villa de Daimiel a someterse a el [sic] General Sebastiani y desde allí cuatro de ellos a la Corte de Madrid [...] y rendir el vasallaje a el [sic] Rey Intruso, con la circunstancia de que si bien pudieron por efecto del terror someterse a el [sic] Juramento que habrían evitado observando la conducta de la Junta, y demás personas distinguidas, no así sucedió en razón de la ida a la Corte; porque ya se habían marchado los franceses de Infantes cuando verificaron esta. Se hallaban con una efectiva libertad y con la proporción de la proximidad de nuestro ejército que apenas distaba tres leguas del pueblo, donde pudieran haberse refugiado para libertar sus vidas y aun cuando quisiesen cubrirse con aquello de que lo hacían por redimir vejaciones al pueblo mucho menos temible le habría sido su desolación a sus moradores leales que el de estimarlo sometido y jurada la obediencia a el Rey Intruso" ${ }^{19}$.
\end{abstract}

El resto de los miembros de la Junta, en escrito dirigido inmediatamente a las autoridades patrióticas, se desvinculan de este acto personal y expresan su enérgico rechazo ante estos hechos, haciéndose representantes de la opinión de la mayoría de la población. Aseguran en él que el pueblo se negó a contribuir con los traidores y los invasores, negándose a facilitarles los carruajes que necesitaban para trasladarse a la Corte (dejando huir a las caballerías) y los demás tributos que estos pedían, siendo por ello amenazados por el regidor de que responderían ante el general francés por ello, que quemaría sus hogares y sus bienes.

Así, tras la retirada de los franceses y el regreso de los vocales de la Junta a Infantes, siguiendo los preceptos de la Junta Provincial de La Mancha, se decidió retirar de su cargo de presidente al anterior alcalde, quedando como tal el más antiguo de los miembros de la Junta. Se pide, asimismo, la retirada de su puesto de administrador de justicia del anterior alcalde mayor y del regidor, Miguel Ortega, habiendo tenido noticia de estar depositada ésta en sus manos. Y, finalmente, exigen la

19 Todas las referencias al hecho narrado corresponden a AHN, Estado, leg. 83T. 
publicación en las gacetas españolas la publicación de su versión de los hechos referidos: que el juramento de fidelidad a José I de la Villa de Infantes había sido únicamente obra de la voluntad y arbitrariedad del juez y regidor, siendo mayoritario el rechazo de la nobleza y hombres de honor del pueblo.

No sabemos si el relato que de estos hechos elaboran los miembros de la junta de defensa de Infantes responde al desarrollo exacto de los mismos, sobre todo en lo referente a las motivaciones que tuvieron Ortega y los demás vecinos para jurar lealtad a los franceses. Sorprende, sin embargo, que tras la retirada de los franceses y el restablecimiento de la autoridad de la Junta, siguiendo los preceptos de la Superior de La Mancha, se juzgase a Ortega con tibieza: únicamente se le retiró del cargo de presidente de la Junta local (quedando en su lugar el más antiguo de los vocales) y administrador de la justicia.

\section{LA TRANSFORMACIÓN DE LAS ESTRUCTURAS SOCIO-ECONÓMICAS}

Si en el plano político los cambios quedaron reducidos a un plano más bien simbólico, las transformaciones se ahondaron en lo referente a las estructuras sociales y económicas del Antiguo Régimen, al trastocarse irremediablemente las relaciones de producción tradicionales.

A principios del siglo XIX, las tierras del partido judicial de Villanueva de los Infantes presentan una estructura económica de base esencialmente agraria, quedando esta actividad condicionada por una serie de problemas estructurales como la escasa calidad de la tierra de cultivo, la falta de agua y el peso de las vinculaciones, así como por la utilización de técnicas rudimentarias, las periódicas plagas de langosta y la falta de una mínima dotación de infraestructuras y una conveniente red de transportes. El cultivo más extendido en esta zona era el cereal de secano, principalmente trigo (cubría aproximadamente el sesenta por ciento de la producción), aunque en algunos de los pueblos del partido se recogían también garbanzos y legumbres, se cultivaba azafrán y se producía aceite y vino.

Esta economía agraria se completaba con la actividad ganadera, especialmente importante en las dehesas de Villanueva de los Infantes y Campo de Criptana, destacando las cabañas de ganado mular y vacuno, aunque también se estabulaban ovejas y cabras. La caza y la pesca, así como la recogida de miel en los pueblos colindantes a Sierra Morena completaban el abanico de recursos económicos de estos pueblos.

Respecto a la industria y el comercio, la situación era de un casi total estancamiento. Fundamentalmente era una producción dedicada a manufacturas tales como paños, fajas, ligas o tejidos de lana, algodón, 
estambre, blondas o encajes y a la elaboración artesanal de alfarería, jabón, chocolates, etcétera. Existía también en el partido alguna fábrica de pólvora, salitre, bermellón, lacre y hornos de cal y yeso, pero sobre todo abundaban los molinos. Sí resulta llamativo que, a pesar de que este territorio contaba con abundantes recursos minerales (plata en Fuenllana y Torre de Juan Abad; plomo en Villamanrique; cobre en Montiel y en Villanueva de los Infantes; hierro en Albaladejo y Villanueva de la Fuente; antimonio en Torrenueva; y carbón de piedra en los territorios de Ruidera) estos apenas se explotaban. Respecto al comercio, en una época en que aquél se nutría esencialmente de las ferias, no hay ninguna importante a destacar en las tierras infanteñas, aunque probablemente se celebraran mercados semanales de cierta relevancia ${ }^{20}$.

La estructura socio-económica retratada en los párrafos anteriores coincidiría con el modelo económico de interior que definió Agustín Y. Kondo, el de una sociedad agraria regida por unas relaciones de producción básicamente señoriales, pues serían la nobleza y el clero quienes aglutinarían la propiedad de la tierra frente a la mayoría campesina, jornalera. Asimismo, la clase media apenas se encontraría desarrollada, conforme a la escasa presencia de una economía comercial e industrial21.

La debilidad de la economía de estos pueblos quedaba patente en la episódica aparición de crisis de subsistencias, entre las más duras de las cuales han de mencionarse las producidas en los años de 1801 y 1804, como consecuencia de las escasas cosechas que la climatología y la langosta habían permitido recoger esos años. Esta delicada situación se va a agravar, lógicamente, con la invasión francesa, pues el estallido del conflicto obligó al establecimiento de una suerte de economía de guerra marcada fundamentalmente por las requisas de alimentos, ganados, armas, recursos pecuniarios y medios de transporte por parte de cuantos ejércitos transitaban por el partido (francés, español, angloportugués y, por supuesto, también la guerrilla). Los impuestos y las requisas afectaron primero a los concejos municipales y cuando estos quedaron arruinados, el pago correspondiente al municipio pasó a repartirse entre sus vecinos.

Los impuestos agobiaban a la población, que se veía constantemente requerida por las autoridades de uno u otro bando a exprimir sus escasas economías. El 22 de agosto de 1808, por ejemplo, la Junta Superior de La Mancha exigía a la de Villanueva de los Infantes una contribución de más de dos millones de reales, repartidos entre los pueblos de su partido, que habrían de ser entregados en el término de quince días

20 J. de Hosta, Crónica de la provincia de Ciudad Real, vol. II, Madrid, Aquiles Ronchi, 1865 , p. 40 y ss.

21 A. Y. Kondo, La agricultura española del siglo XIX, Madrid, Nerea, 1990. 
desde la recepción de su comunicación. La recaudación debería hacerse, según indicación expresa del oficio, "sin excepción de clases, cargando según los réditos anuales, de cualquier naturaleza que sean, a todos los eclesiásticos, así seculares como regulares, comunidades, terratenientes, forasteros, empleados y comendadores de órdenes"22. En la misma línea se sitúan otros muchos requerimientos, que exigen la colaboración de los municipios con víveres, monturas, carros y, por supuesto, hombres. Ahora bien, estos no siempre se mostraron solícitos a colaborar con sus superiores, manifestando en más de una ocasión su dolor "al encontrarse en el día sin arbitrios para suministrar los auxilios que quisiera" 23 .

En el caso concreto de la junta de Infantes, el conflicto de autoridad con la de Ciudad Real sirvió como excusa para incumplir sus requerimientos hasta la resolución del contencioso. Por ello desoyó sistemáticamente oficios como el siguiente, emitido en el verano de 1808 por la junta manchega, urgiéndole a que "se sirva disponer que en el preciso término de tres días se conduzcan a esta capital todos los caudales [que] existan en poder de los arrendatarios de las encomiendas de los señores de Infantes acompañando una relación jurada de su procedencia con distinción de ramos y de los rendimientos de cada una según el último quinquenio, expresando al mismo tiempo si en ese partido existe alguna otra que se disfrute por sujetos particulares, quiénes son, en qué pueblos $\mathrm{y}$ en la misma forma los productos anuales" 24 .

Los restantes pueblos del partido pagaban con la misma moneda a las autoridades de su cabeza de partido, negándose a contribuir al esfuerzo bélico y eludiendo siempre que pudieron los impuestos y contribuciones. Fue una desobediencia institucional e individual. En plena guerra, los señores Justicia y Ayuntamiento de Villahermosa desoyeron un oficio del gobernador de Infantes, Juan Álvarez Lorenzana, quien solicitaba a la misma el avituallamiento de las tropas francesas que marchaban desde Toledo y Aranjuez hacia Andalucía a su paso por la localidad con "bienes y utensilios, carros, bagajes y cuanto necesiten". Concretamente, se les asigna la entrega de doce carruajes y sesenta arrobas de criadillas y patatas, "que traerán estos y deben estar en ésta el 26 para trasladarse a Manzanares el 27 en la noche" 25 . Sin embargo, al no enviarse ningún comisionado de Infantes que guardase el viaje, planearon los propietarios de los carros regresar a su domicilio y así lo hicieron. No se presentaron, pues, los carruajeros en Manzanares, lo cual motivó el envío de un oficio del Alcalde Mayor de esa villa urgiendo su envío inmediato y

22 AHN, Consejos, leg. 5518, exp. 8.

23 Ídem.

24 Ídem.

25 Ídem. 
el castigo de quienes hubieran tenido parte en esa acción. Requeridos a presentarse en la madrugada para iniciar el envío a Manzanares de sus carros de un par de mulas, volvieron a ignorar las exigencias de la junta de Infantes. Esta misma actitud fue adoptada por algunos vecinos a título personal. Tal fue el caso de Manuel Pérez, vecino de Torrenueva, quien se fugó con un par de mulas que las autoridades francesas pretendían que entregara.

En algunos casos, los pueblos, para evitar la presión sobre los vecinos y para aminorar la tensión social, agudizada por esta situación, optaron por soluciones intermedias. Tal fue el caso de Membrilla, donde en 1809 se acordó la elaboración de una lista con los labradores de más de una yunta y los panaderos que tuvieran una mula para sortear entre ellos la aportación requerida por los poderes competentes. El procedimiento sería el siguiente: una vez elaboradas las listas, se darían cédulas por cada par de mulas en el caso de los labradores, por cada res en el de los panaderos; cada grupo se depositaría en un cántaro para, llegado el momento de los bagajes, extraer de los mismos por suertes las papeletas necesarias; para garantizar la limpieza del proceso las cántaras se guardarían en casa del alguacil mayor, Luis Díaz Pintado y el sorteo tendría lugar en presencia de los señores Antonio Martín de Pedro Alonso, Pedro Menchén, Alfonso Herreros y Manuel Muñoz Alcaide en representación de los labradores y de Juan Cotillas Romero, procurador síndico general en nombre de los panaderos, que actuarían como testigos. Los resultados del sorteo se anotarían, además, en un libro, custodiado también por el alguacil ${ }^{26}$.

Otro capítulo interesante en esta historia de resistencias al pago de tributos o a la colaboración material de los pueblos del partido es el que protagonizaron las juntas de La Solana y Manzanares durante el verano de 1808. Los hechos se inician en el mes de julio cuando esta última se dirige a la junta de La Solana para que, con motivo del establecimiento de una división de caballería del ejército de Andalucía en la localidad, se entreguen doscientas fanegas de cebada para el surtido de la tropa. Ignorada completamente esta primera misiva, desde Manzanares vuelve a insistirse una vez más en agosto para comunicar que quedan arbitrados todos los diezmos, fondos y pertenencias de las encomiendas de esta villa, las de Valdepeñas, Membrilla, Argamasilla de Alba y Tomelloso, con los agregados de sus contadurías respectivas, para el sostenimiento del Ejército de Andalucía, al mando del General Castaños. En consecuencia, se les requiere la pronta recaudación de caudales y venta de frutos, remitiendo las cantidades que produzcan a disposición de la

26 P. Almarcha Jiménez, La guerra de la independencia en Membrilla (1808-18914), Membrilla, Ayuntamiento de Membrilla, 2008, p. 29. 
Junta de Manzanares. Además, dice que, teniendo conocimiento de que la Junta ha hecho uso ya de algunas de las existencias de su Encomienda, les urge a que las reintegre de los dos tercios de contribuciones vencidas, omitiendo el pedido de otras; y que urja a los vecinos en general o en los casos particulares que se requiera a que cobren apresuradamente sus diezmos y descubiertos a favor de la Encomienda.

Sólo un mes más tarde, Manzanares se comunicaba nuevamente con La Solana para exigirle, debido al establecimiento en su término de más de nueve mil hombres, Intendencia y Contaduría de Ejército, Tesorería, Administración de Correos, Imprenta e Intendencia y Contaduría de Víveres, la aportación de doscientas fanegas de cebada "de que se han desentendido", seiscientas raciones de pan diarias y cuarenta arrobas de aceite, "pues en esta villa carecemos hasta para el consumo del pueblo por el excesivo que ha habido en las tropas francesas y españolas". Finalmente, la junta de La Solana contesta negándose a colaborar, aduciendo la inexistencia de datos de seguridad que den veracidad al oficio anterior. Pero desde Manzanares se atribuye la desobediencia a la voluntariedad de la junta, pues "hemos pedido ya varias veces la cebada y se han desentendido Ustedes; hemos pedido carruajes y cuando lo hemos hecho de diez, han venido dos, y sólo una vez han sido siete, enviándonos los trajinantes con sus cargamentos. La División se halla ya en la mayor parte en esta villa y el resto entra mañana en ella; y vean ustedes este dato tan fijo y que demuestra que su contestación es (ingenuamente hablando) una verdadera evasión". Por esta razón, se urge a que sin, dilación, al día siguiente estén los suministros en Manzanares (a los que ahora se sumaría cincuenta arrobas de aceite y la obligación de que "vengan a vender tocino al mercado los que lo tengan"), viéndose obligada la junta a tomar los medios de reclamación oportunos si no fuera así.

La junta de La Solana no se arredraría ante las amenazas y se justificaría indicando que no había enviado caballería alguna por carecer de ellas y se queja de otras requisas abusivas, como aquélla de cuatrocientas camas de la que resultó "un tan conocido perjuicio al vecindario que no puede mirarse sin dolor". Los desencuentros continuarían entre ambas localidades y, finalmente, ambas apelarían a la autoridad del Consejo de Castilla para dirimir sus diferencias, el cual estableció que no se entregase caudal público alguno ni se satisficiesen las cantidades que se intentasen exigir al pueblo, procurando la más pronta cobranza de los propios y rentas que deberían conservarse para ocurrir, entre otros gastos, a los de armamento, manutención y socorro de los que se alistasen para el servicio militar. Resulta especialmente significativa la proclama que hace la junta de La Solana en su recurso al Consejo: 
"Tú [se refiere a la Junta de Manzanares] has recogido el dinero de las Administraciones, tú has tomado los intereses de tu Encomienda, el dinero de Correos, las existencias de provisiones y después has hecho contribuir a las villas inmediatas con harina, con pan, con ganado, con vino, con carruajes y mulas, qué haces de aquellos fondos [...] Queremos orden, queremos formalidad" ${ }^{27}$.

Todos estos ejemplos de desobediencia de las autoridades provisionales al pago de los tributos y contribuciones exigidas por sus superiores son una clara evidencia de que se ha iniciado un proceso clave en el desmoronamiento de las relaciones socio-económicas de producción propias del Antiguo Régimen. Un proceso que, no obstante, ya se había iniciado con anterioridad al conflicto, y cuyas raíces se hunden en la pérdida de tierras de una buena parte de la población agrícola a finales del siglo XVIII, lo cual habría derivado en un incremento de la tensión social que habría llevado a aquéllos, incluso, a arruinar las cosechas de los grandes señores ${ }^{28}$. La excepcionalidad de la coyuntura bélica simplemente habría agudizado la problemática.

Otro proceso clave en la disolución de las relaciones sociales y de producción propias del Antiguo Régimen fue la desamortización iniciada por el gobierno bonapartista, que decretó la nacionalización de los conventos y sus propiedades: los bienes de la Orden de Santiago, por ejemplo, se utilizaron para pagar a quienes demostraban su fidelidad al nuevo régimen $\mathrm{y}$, en muchas localidades, los conventos e iglesias fueron utilizados como cuarteles, almacenes y polvorines. De la administración de los nuevos bienes nacionales se encargó en la provincia de La Mancha Gabriel Tagle. Otros trabajos más extensos han señalado ya las dificultades para cuantificar el alcance del proceso desamortizador, pero también han subrayado su impacto en los resortes de supervivencia económica de instituciones vitales del Antiguo Régimen como la Iglesia o los municipios, cuyas tierras fueron roturadas ${ }^{29}$.

La liberación del peso que suponían los pagos jurisdiccionales y la mercantilización de la tierra acercaban las relaciones productivas cada vez más hacia formas capitalistas, alimentando la ilusión de los labradores de convertirse en propietarios. Una ilusión que, como ha indicado Carlos Javier Rubio, ya estaba presente entre los menestrales y criados de labor del Campo de Montiel desde finales del siglo XVIII, que aspiraban a convertirse en pegujaleros o labrantines, actitud que un informe

27 Sobre el conflicto entre ambas juntas, AHN, Consejos, leg. 5518, exp. 8.

28 En J. López-Salazar Pérez, "Evolución demográfica de La Mancha en el siglo XvIII", Hispania, núm. 133, 1976, p. 281. Citado por R. Fraser, ob. cit., p. 384.

29 A. Monescillo y A. R. del Valle, ob. cit., pp. 371-372. 
del ayuntamiento de Infantes condenaba ya por el año 1794 porque llevaba a la desocupación de sus actividades principales y al endeudamiento de la población campesina ${ }^{30}$. En todo caso, se había abierto una brecha en las relaciones de producción tradicionales que se ahondaría cuando las Cortes de Cádiz decretaran en 1813 la venta de baldíos, marcando una vía que sancionaría irreversiblemente la desamortización de Mendizábal en 1836.

Otro elemento a valorar en este análisis es la situación extrema en que se encontraba la población. Si el pueblo no estaba suficientemente asfixiado por las requisas y arbitrios, así como por la escasez que se derivaba de la falta de trabajadores agrícolas, que o habían muerto o se encontraban batallando en el conflicto, a todo ello había que sumar los saqueos de las tropas francesas, que esquilmaban aún más las empobrecidas economías populares. Durante la retirada, a finales de verano y el otoño de 1812, este tipo de actuaciones se intensificaron. Como ejemplo de lo que ocurrió en otros muchos pueblos del partido podemos tomar la siguiente crónica de lo sucedido en El Hinojoso de la Orden:

\begin{abstract}
"En la noche del 17 al 18 de agosto a cosa de las diez se nos entraron por las calles 29 dragones con espada en mano [...] iban acuchillando a hombres y mujeres sin perdonar ninguna edad. La gritería de las gentes que se veían atropelladas, los clamores de los heridos, el estruendo de los caballos, la confusión, todo presentaba una imagen de la desolación. Nadie sabía qué hacer: peligro en las casas, golpes en las calles y falta de seguridad en todas partes, mayormente para los que querían huir del pueblo, que estaba cercado. Cuando estuvieron bien satisfechos de haber difundido la consternación se apearon algunos, y llevando a palos a la justicia a la cárcel, comenzaron el saqueo general acompañado de todo género de violencias. Extrajeron todos los granos, quemaron los carruajes, y en las mulas de labor se llevaron cuanto era portátil; de modo que en pocas horas nos hallamos sin un grano, sin ganados, sin utensilios de labranza, muchos heridos, no pocos contusos, y todos en el desamparo" ${ }^{31}$.
\end{abstract}

Lógicamente, la crisis económica tuvo su correlato demográfico, observándose un descenso generalizado de la población en los pueblos del partido, como consecuencia del estancamiento de la natalidad y el notable aumento de la mortandad, especialmente intensa en el periodo de 1809 cuando la guerra se encontraba en su punto más álgido en la

30 C. J. Rubio Martínez, ob. cit., p. 27 y ss.

31 Gazeta Superior de La Mancha, tomo 155, 10-10-1812. AGM, Colección documental del Fraile, vol. 135. Tomado de F. Molina Carrión, op. cit., pp. 138-139. 
zona. Si esta demarcación contaba con una población cercana a los veintinueve mil habitantes según el censo de Floridablanca de 1787, el vecindario de las villas del partido de Infantes elaborado por Casimiro A. Bontempo en 1809 rebajaba esta cifra a los 23.465 habitantes $^{32}$. Este descenso poblacional se hizo especialmente notorio en localidades como Alcubillas, Castellar de Santiago, Carrizosa y Villanueva de los Infantes, donde la actividad bélica fue más acusada. No obstante, además de las bajas debidas directamente al enfrentamiento armado, habría que tener en cuenta otros factores de mortandad como las epidemias (sobre todo de enfermedades palúdicas y tifoideas que se cebaron con la población en el verano de aquel año) y el empeoramiento de la alimentación.

\section{LAS ALTERACIONES EN LA VIDA COTIDIANA DURANTE LA GUERRA DE INDEPENDENCIA}

Como lógica consecuencia del contexto bélico, la vida cotidiana en el partido de Infantes resulta algo convulsa y anómala en estos años. Por un lado, la carestía derivada de la escasez de cosechas y la carga de las contribuciones y requisas, había azuzado la conflictividad social, incrementándose los robos, la rapiña y los motines populares. Fue esta una de las razones más importantes por las que se constituyeron las juntas de defensa. La misma junta de Infantes así lo reconoce cuando escribe que su creación tenía como objetivo "contener tan graves atentados, cuyo menor perjuicio sería la insubordinación a las autoridades legítimas cuando era más necesario mantener el orden para ponerse a cubierto de los males experimentados en casi todos los pueblos y provincias por la efervescencia del pueblo, poco acostumbrado a calcular las consecuencias fatales que trae consigo la menor alteración del orden establecido" 33 .

Desde sus filas se incidió en la necesidad de vigilar el cumplimiento de los bandos de las autoridades patrióticas en los pueblos de su competencia, "con el objeto de que resulte la mayor tranquilidad y evite en el vecindario todo motivo de alteración en sus individuos ni fomento de alborotos causativos de perniciosas consecuencias y motines" 34 . Por eso, además de bandear las disposiciones de la Junta Suprema, como poder delegado del mismo rey, aquéllas se expondrán al público durante las horas de audiencia ante las puertas de las casas del presidente de la Junta

32 Bontempo, escribano del rey y secretario de la junta de gobierno de Infantes, elaboró este vecindario en cumplimiento de lo ordenado por decreto de 12 de noviembre de 1809 para la regulación de cada villa en la ayuda prestada al ejército. Tomado de J. Jiménez Ballesta, El Campo de Montiel 1808-1814. Guerra de la Independencia, [s.l.], Ediciones Llanura, 2008.

33 AHN, Consejos, leg. 5518, exp. 8.

34 Ídem. 
local "por el espacio de tiempo que baste a que todo el pueblo se entere y ninguno de sus vecinos jamás pueda alegar ignorancia". Con el objeto de hacer más efectivos sus mandatos, en el mes de julio de 1808, se creó también un cuerpo de vigilancia "para el mejor orden y sosiego de la tranquilidad pública" 35 .

Llegó la situación a tal extremo que la misma Junta Suprema se vio compelida a intervenir y así envió a la provincia de La Mancha a un oidor para acabar con los "asesinatos, desacatos a la Justicia y desórdenes de consideración" ${ }^{6}$ que allí se estaban produciendo. El encargado de tal tarea fue el oidor de la Chancillería de Granada Francisco León Bendicho, que tan pronto llegó a nuestras tierras, en febrero de 1809, pudo dar cuenta de la "considerable porción de malévolos y asesinos [que] fomentan especialmente las insurrecciones en esta Provincia" ${ }^{37}$.

Por otra parte, los fusilamientos, asesinatos y demás formas de depuración político-ideológica extendieron el miedo entre los habitantes del partido, que en buena parte de los casos huyeron despavoridos hacia el campo o hacia las poblaciones vecinas en cuanto se avistaban las tropas francesas. Hasta 1809, pueblos como Torre de Juan Abad, Membrilla, Alhambra o el propio Infantes habrían recibido población huida de otras poblaciones atacadas, como han demostrado los estudios de Eva Jesús Morales sobre los huidos de Valdepeñas ${ }^{38}$; sin embargo, a partir de esta fecha, la población de estas villas se habría visto forzada a tomar el mismo camino. No era una reacción exagerada, desde luego, a la vista del relato que la propia junta de La Mancha hace de la situación que presentaban algunos de estos pueblos tras el paso de las tropas francesas en el verano de 1809:

"Los pueblos desiertos, las casas yermas y arruinadas, la suciedad y el hedor intolerable de ellas, presentan al que las mire más bien una idea de una habitación de fieras que de hombres. El peso de las desgracias, el hambre y la intemperie han acabado en los montes con un sin número de familias; $y$ estos fieles vasallos, abandonados tanto tiempo a la rapiña, y a las violencias más execrables de los verdugos de la humanidad, aún bendicen a los que viene a amparar y alargan con generosidad sus albergues y sus cortos residuos de sus bienes a nuestros soldados" 39 .

35 Ídem.

36 AHN, Estado, leg. 31G.

37 Ídem.

38 E. M. Jesús Morales, "La Guerra de la Independencia en Valdepeñas y su vinculación con el Campo de Montiel”, Anuario Jurídico y Económico Escurialense, XLII (2009), pp. 551-570.

39 AHN, Estado, leg. 63C. 
Infundidos por el temor, muchos de ellos se resistían a volver a sus localidades de origen, por lo que el Intendente provincial, Florentino de Sarachaga, habría ordenado a las autoridades del partido a que conminaran a sus habitantes a volver a sus respectivas poblaciones bajo amenaza de confiscación de todos sus bienes.

Entre quienes rechazaron la posibilidad de huir y decidieron hacer frente al francés invasor, destacan sin duda aquellos que optaron por unirse a la guerrilla. Sin pretender cuestionar el patriotismo que habría inspirado esta acción de resistencia, es cierto que hay que tener en cuenta otros elementos importantes para explicar su aparición. En primer lugar, este modo de hacer la guerra, por su naturaleza, daba mayores garantías de supervivencia que las que existían en el ejército regular, inferior en todos los aspectos al napoleónico, de ahí que se produjeran numerosas deserciones; como Celedonio de Barredo explicaba al General Blake, jefe del Ejército del Centro en una misiva "algunos soldados naturales de día escriben a sus parientes manifestándoles que esperan el día que haya alguna acción para dispersarse y venirse a las Partidas de Guerrilla" ${ }^{40}$. En julio de 1808 la Junta Suprema se vio obligada, incluso, a dictar normas contra los desertores "para evitar los daños que con la deserción se experimenta de nuestros soldados de los ejércitos" 41.

No menos importante resulta el hecho de que la guerrilla permitía simultanear la lucha con las ocupaciones habituales al no estar sujeta a la disciplina militar, garantizando la supervivencia del medio familiar, que se podía ver incrementada con otra clase de recompensas económicas, como las derivadas de los botines de guerra. De hecho, la guerrilla fue una vía hacia una forma de vida alternativa como era el bandolerismo, sobre todo entre aquellos que por su condición de desertores no podían recuperar su vida anterior al reclutamiento. Asimismo, habría que tener en cuenta la tradición previa de movilización social existente que había dado a la población una sensación de autosuficiencia; es el caso, por ejemplo, de la formación del rondín, una suerte de cuerpo de vigilancia que se había creado a principios del siglo XIX en villas como Infantes para mantener el orden en la población ${ }^{42}$.

Que los habitantes del partido estaban dispuestos a luchar, pero no a entregarse a una muerte probable entre las filas de un ejército patriótico claramente inferior a la potente maquinaria militar napoleónica lo demuestran las dificultades con que se encontró la Junta de Infantes

40 AHN, Diversos-Colecciones, leg. 128, exp. 23.

41 AHN, Consejos, leg. 5518, exp. 8.

42 Ver J. S. Pérez Garzón, "Guerra y revolución: el inicio de la época contemporánea en CLM”, en F. Ruiz Gómez (dir.), Castilla-La Mancha en su historia, Toledo, Junta de Comunidades de Castilla-La Mancha, 2009. 
para cumplir con los cupos de reclutamiento que le correspondían. En el otoño de 1808 , por ejemplo, hubo de dirigirse a sus autoridades superiores para comunicarles la imposibilidad de enviar los seiscientos hombres que correspondían al partido, al haberse alistado únicamente un total de ciento cuarenta y uno. Aun cuando la Junta envió la circular con los hombres que correspondían a cada pueblo, unos lo satisficieron sólo parcialmente y otros directamente se negaron a colaborar, a pesar de las amonestaciones que la Junta les profirió. Cuando se interrogan sobre las causas de este estado de cosas aparece un tercer elemento a valorar: el mal ejemplo de los poderosos. Dice, textualmente, la misiva enviada por la Junta:

\begin{abstract}
"Una de las causas que conceptúan haya influido en la frialdad con que se han conducido la mayor parte de los mozos alistados, conceptúan sea la de que los manejantes y caciques de los pueblos, a quienes incumbía dar ejemplo, se han retirado y lo han hecho según noticias a aquellas personas de su familia y amistad" ${ }^{43}$.
\end{abstract}

Fueron muchas las partidas que actuaron en el partido de Infantes, entre las que se pueden mencionar las del médico José Martínez de San Martín, Francisco Abad Moreno Chaleco, Miguel Díaz, don Ventura, Juan Martínez Díaz El Empecinado o Francisco Sánchez Francisquete.

Finalmente, no se puede dejar de señalar cómo en un contexto totalmente anómalo como era el de la guerra de Independencia y ante la falta de atención de las autoridades encargadas de la vigilancia de las "buenas costumbres", ocupadas en tareas más acuciantes, no resulta extraño que se subvirtiesen algunas convenciones sociales y morales. Incluso, algunas instituciones vitales en esta tarea de vigilancia, como la Inquisición, fueron abolidas por las Cortes de Cádiz.

La presencia de las tropas invasoras en el Campo de Montiel a partir de diciembre de 1809 y hasta el verano de 1812 fue una fuente de tensión en este sentido y también un foco de problemas, debido a los alborotos públicos que causaron en las poblaciones. Los casos de abusos sexuales llegaron a ser frecuentes, aunque en ocasiones el establecimiento de relaciones con los franceses fue consentido. En general, durante los años que duró la guerra las relaciones entre ambos sexos fueron llevadas con una mayor permisibilidad. No es de extrañar, pues, que durante estos años se produjese un notable incremento del nacimiento de hijos fuera del matrimonio (como demuestra el aumento de la inscripción en los registros bautismales de hijos "de padre no conocido"), así como del

43 Ídem. 
abandono infantil entre los diferentes estamentos sociales. Son numerosos los testimonios registrados por los eclesiásticos sobre el hallazgo de niños expósitos ante las puertas de los vecinos de mejor posición de sus respectivas localidades. Algunos de ellos, como el siguiente, nos ofrecen una gran riqueza de detalles:

\begin{abstract}
"El 15 de julio de 1808 [...] bapticé sub conditione a un niño hijo de padres no conocidos, que en la madrugada de este día pusieron encima de un carro que se allava [sic] a las puertas de Gregorio Jaime, calle de Almenas, siendo como a las dos de ella, y llamaron por dos veces, diciendo saliesen a recogerle. [Estaba] envuelto en una mantilla pajiza, su pañal viejo, camisa buena, su gorro, liado con su faxa echa [sic] de dos ligas; y un lío en el que traía otra camisa nueba [sic], otro pañal bueno y otro gorro, su rodeador y una esquela que decía: "Cirilo Tomás Thadeo me llamo, agua traigo", y todo envuelto en un pedazo de tendido, púsele dicho nombre. Fue su madrina Catalina Villalba" ${ }^{44}$.
\end{abstract}

\title{
CONCLUSIÓN
}

1812 es un año cargado de simbolismo en la historia contemporánea española, al ser la fecha que alumbró nuestro primer texto constitucional, dando carta de naturaleza a la revolución liberal en nuestro país. Lo es también para el partido de Villanueva de los Infantes, al ser esta villa la elegida para su juramento por la Junta Superior de La Mancha, al ser la primera de la provincia en acatar el texto constitucional. Sin embargo, 1812 es mucho más que la antesala de un trascendental cambio político. Es también un año fundamental en la erosión institucional del Antiguo Régimen, así como en la desintegración del sistema de relaciones socio-económicas que le es propio. Un proceso que, sin duda, la coyuntura bélica empujó y aceleró, al proporcionar el contexto necesario para el cambio: la ausencia del poder monárquico inspiró una nueva forma de organización como las juntas, que se hacían depositarias de la soberanía nacional, lo cual supuso el primer asalto del liberalismo al poder político; además, las resistencias al pago de los tributos y la nacionalización de los bienes eclesiásticos y municipales dinamitaron las estructuras socio-económicas feudales que aún quedaban en pie. Ambos procesos se complementan con la aparición de nuevas formas de vida asociadas a esta realidad convulsa y anómala y, sobre todo, con la subversión de algunas convenciones socio-

44 APSAA, Libro de bautismos, fol. 295. Citado por E. M. Jesús Morales, ob. cit., p. 567. 
culturales tradicionales. Todos y cada uno de estos fenómenos han sido abordados a través del espacio geográfico y administrativo del partido judicial de Villanueva de los Infantes que fue partícipe en estos años de la entrada de nuestra región en la contemporaneidad.

Relación de siglas empleadas

AGM: Archivo General Militar

AHN: Archivo Histórico Nacional.

APSAA: Archivo Parroquial de la Iglesia de San Andrés Apóstol de Villanueva de los Infantes. 